ISSN 1991-8631

Original Paper

http://indexmedicus.afro.who.int

\title{
The effect of Yoyo bitters on the pharmacokinetics of single oral dose paracetamol tablet in human volunteers
}

\author{
Bulus Vilret KUMDI, Jacob A. KOLAWOLE* and Emmanuel APEH \\ Department of Pharmaceutical Chemistry, University of Jos. Jos. Nigeria. \\ *Corresponding author,E-mail: kolaja@unijos.edu.ng, kolajac@yahoo.com , +234 8033669695
}

\begin{abstract}
Paracetamol (Tylenol, acetaminophen) and Yoyo bitters (a liquid oral herbal preparation) are known prescriptive drugs and widely available to "patients". They are taken individually or as combination therapy at slightest signs/symptoms of fever in Nigeria. The pharmacokinetics of oral single dose paracetamol (1000 mg tablet), was evaluated in eight healthy male volunteers. Experiment was carried out in three phases. In the $1^{\text {st }}$ phase, only oral paracetamol tablet was administered to subjects, while in the $2^{\text {nd }}$ phase, subjects were administered paracetamol at the same time with Yoyo bitters and in the $3^{\text {rd }}$ phase, (delayed protocol) the subjects were administered paracetamol after taking Yoyo bitters for 3 days. Blood samples were collected and analyzed for paracetamol using spectrophotometric method. The values obtained for the pharmacokinetics parameters when paracetamol was administered alone falls within previously reported values. Yoyo bitters did not statistically $(\mathrm{P}>0.05)$ affect the pharmacokinetics of paracetamol when administered concurrently with Yoyo bitters. However when administered after three days of Yoyo bitters administration, there was statistically significant $(\mathrm{P}<0.05)$ increase in $\mathrm{AUC}_{0-\infty}$ and $\mathrm{t}_{1 / 2 \beta}$ while there was significant $(\mathrm{P}<0.05)$ decrease in $\mathrm{K}_{\beta}$ and $\mathrm{Cl} / \mathrm{F}$.

(C) 2011 International Formulae Group. All rights reserved.
\end{abstract}

Keywords: Paracetamol, (acetaminophen, Tylenol), Pharmacokinetics, Drug-drug interaction, Herb-drug interaction.

\section{INTRODUCTION}

Yoyo bitters is a galenical oral preparation made from a blend of various parts and fruits of plants such as; Aloe vera, Cinamum aromaticum, Citrus aurantifolia, Acinos arvensis, Chenopodium murale. It is claimed by the producers to be formulated for use in the following conditions; to prevent kidney and bladder infections, normalize intestinal movement, help regulate blood pressure, facilitate digestion and to prevent disorders like ulcers, gastritis, insomnia, stress and depression and control of body weight. It is also recommended for the maintenance of general well being of the body.

Drug interaction is a common phenomenon in medicine that is said to occur when the effect of one drug is changed by another drug, food, drink or environmental chemical agents. The absorption of drugs from the gastrointestinal tract is complex and variable, making drug interaction of this type difficult to predict. It is important to recognize that the majority of these interactions result in changes in absorption and disposition rates. A number of xenobiotics influence drug 
metabolizing enzyme activities either by inhibiting or inducing the enzyme.

Orally administered paracetamol is well absorbed from the gastrointestinal tract (GIT) and was reported to have a peak plasma concentrations $\left(\mathrm{C}_{\max }\right)$ of $18.2 \mathrm{mg} / \mathrm{ml}$ with a $\mathrm{T}_{\max } 0.5-2.0 \mathrm{~h}$, and elimination half life $\left(\mathrm{t}_{1 / 2}\right)$ of 1.25-3 h (Flower et al., 1985).

Paracetamol is primarily metabolised by two isoenzymes of cytochrome P450: CYP2E1 and CYP1A2. The P450 gene is highly polymorphic, however, individual differences in paracetamol toxicity are believed to be due to a third isoenzyme, CYP2D6. Genetic polymorphisms in CYP2D6 may contribute to significantly different rates of production of NAPQI. Furthermore, individuals can be classified as "extensive", "ultra rapid", and "poor" metabolizers (producers of NAPQI), depending on their levels of CYP2D6 expression (www.wikipedia.org, 2009).

Paracetamol hepatotoxicity is, by far, the most common cause of acute liver failure in both the United States and the United Kingdom. Signs and symptoms of paracetamol toxicity may initially be absent or vague. Untreated, overdose can lead to liver failure and death within days.

Typical examples of herb-drug interactions and observed effects include: bleeding when warfarin is combined with ginkgo (Ginkgo biloba), garlic (Allium sativum), dong qual (Angelica sinensis), or danshen (Salvia miltiorrhiza); mild serotonin syndrome in patients who mix St John's wort (Hypericum perforatum) with serotoninreuptake inhibitors; decreased bioavailability of digoxin, theophylline, cyclosporin, and phenprocoumon when these drugs are combined with St John's wort; induction of mania in depressed patients who mix antidepressants and Panax ginseng; decreased blood concentrations of prednisolone when taken with the Chinese herbal product xaio chai hu tang (sho-saiko-to); and decreased concentrations of phenytoin when combined with the Ayurvedic syrup shankhapushpi.
Anthranoid-containing plants (including senna [Cassia senna] and cascara [Rhamnus purshiana]) and soluble fibres (including guar gum and psyllium) can decrease the absorption of drugs (Roby et al., 2000; FughBerman and Ernst, 2001). Pharmacokinetic results show that chronic grapefruit juice (GFJ) ingestion has a great influence on paracetamol metabolism, slowing it down (Samojlik et al., 2002). Paracetamol has severally been reported to interact with drugs, food, beverages/drinks and oral contraceptives (Villeneuve et al., 1983; Adzu et al., 2001; Kolawole and Maduenyi, 2004; Tripathi, 2009). The study was aimed at investigating the effect of Yoyo bitters (a herbal oral preparation) on the pharmacokinetics of oral single dose paracetamol in human volunteers. To the best of our knowledge there are no reports in the literature on the interaction of these drugs.

\section{MATERIALS AND METHODS Materials}

All chemicals were of analytical grade and obtained from the Department of Pharmaceutical Chemistry, University of Jos. Paracetamol tablets (Emzor pharmaceutical industries; manufacturing date 07, 2006; Expiry date 07, 2011; Batch number 3805J) and Yoyo Bitters (ABBLAT Nigerian company Ltd; manufacturing date: December, 2008; expiry date: December, 2009; Batch number: 555; NAFDAC Reg. No. 04-5347L) were purchased from a registered retail pharmacy outlet in Jos.

\section{Subject treatment, sampling time and collection}

This study was approved by the Ethics Committee of the Jos University Teaching Hospital, Jos. All participants received both verbal and written information on the study and gave written informed consent prior to participation. All subjects were nonsmokers and used no concomitant medications. They also abstained from coffee, grapefruit juice, herbal dietary supplements, green tea, and 
alcohol-containing beverages during and 2 weeks before the study period. All participants were in good health as indicated by medical history, routine physical examination. The volunteers were regularly monitored during the experimental period for the development of any possible adverse effect.

\section{First phase (Paracetamol alone)}

The subjects were administered with $1000 \mathrm{mg}$ single dose oral paracetamol tablet with $200 \mathrm{ml}$ of water. Venous blood samples (3 $\mathrm{mL}$ each) were drawn from an indwelling catheter into EDTA bottles immediately before $(0 \mathrm{~min})$ and $0.25,0.5,1,2,3$, and 6 hours after oral administration of paracetamol tablet. Blood samples were centrifuged at $3000 \mathrm{~g}$ for 10 minutes and plasma was collected and stored at $-20{ }^{\circ} \mathrm{C}$ until analysis.

\section{Second phase (Paracetamol concurrent with Yoyo bitters)}

The subjects took $30 \mathrm{ml}$ of Yoyo Bitters 5 minutes before taking $1000 \mathrm{mg}$ of paracetamol. Blood samples were then collected as in first phase.

Third phase (Paracetamol and Yoyo bitters 2 days earlier)

The subjects took $30 \mathrm{ml}$ of Yoyo Bitters for two days before and on the day of sampling. And $1000 \mathrm{mg}$ of paracetamol was administered on the third day 2 hours after the administration of the Yoyo Bitters to the subjects. Blood samples were collected as in first phase.

All blood samples were collected into Disodium EDTA pretreated plastic containers and plasma obtained by centrifuging at $3000 \mathrm{~g}$ for 10 minutes. The collected plasma was stored in a deep freezer at $-20{ }^{\circ} \mathrm{C}$ until analyzed.

\section{Construction of calibration curve}

The calibration curve (standard curve) was obtained by spiking drug free plasma with standard solution of paracetamol $(1 \mathrm{mg} / \mathrm{ml})$, to obtain final concentrations of 0.0, 10.0, 20.0,
30.0, 40.0, 50.0 $\mu \mathrm{g} / \mathrm{ml}$ (Glynn and Kendal, 1975).

\section{Validation of analytical method}

The procedure above was repeated five times for the purpose of validation, on the same day (within day precision) and on five different days (day to day precision). A $0.5 \mathrm{ml}$ of plasma each was spiked with the working solutions 10, 20, 30, 40 and $50 \mu \mathrm{g} / \mathrm{ml}$ of paracetamol and analyzed using the analytical method. Absorbencies were obtained and percentage recovery as well as standard derivation (SD) calculated from the corresponding concentration.

\section{Recovery}

Selected concentrations of stock as in the calibration curve determination were spiked into $0.5 \mathrm{ml}$ of plasma, and also in 0.5 $\mathrm{ml}$ distilled water. The samples were analyzed as in calibration curve and the absorbencies were measured. The corresponding concentrations were obtained and the percentage recoveries calculated.

\section{Data Handling and analysis}

Paracetamol pharmacokinetic parameters were calculated using the noncompartmental method. The peak plasma concentration (Cmax) and time to reach Cmax (Tmax) were obtained directly from the original data. Elimination half-life $\left(t_{\beta}\right)$ was calculated as $0.693 / \mathrm{k}_{\beta}$, where $\mathrm{k}_{\beta}$ is the absolute value of the slope of the terminal loglinear portion of the plasma concentrationtime curve. The area under the plasma concentration-time curve (AUC) was calculated from zero to 6 hours $\left(\mathrm{AUC}_{0-6}\right)$ by use of the linear trapezoidal rule. AUC from zero to infinity $\left(\mathrm{AUC}_{0}-\infty\right)$ was calculated by $\mathrm{AUC}_{0-\mathrm{t}}+\mathrm{Ct} / \mathrm{k}_{\beta}$, where $\mathrm{t}$ is the last measurable sampling time and $\mathrm{Ct}$ is the last measured plasma concentration. Systemic apparent clearance $(\mathrm{Cl} / \mathrm{F})$ of oral paracetamol was calculated as dose/AUC0- $\infty$. 


\section{Statistical analysis}

The pharmacokinetic parameters were presented as Means \pm SD. Treatment effects were evaluated by paired student's ttest with $\mathrm{P}<0.05$ as level of significance.

\section{RESULT}

\section{Validation and analysis}

The result of validation and analysis are presented in Table 1. The calibration curve was found to be linear over a concentration range of $0-60 \mu \mathrm{g} / \mathrm{ml}$ with a correlation coefficient $\left(\mathrm{r}^{2}\right)$ of 0.996 . Percentage recovery was found to be $96.95 \%$ and RSD of 0.0098 . The adapted spectrophotometeric method was therefore efficient enough for the comparative pharmacokinetics and drug interaction study.

The result of the pharmacokinetics parameters are presented in Table 2.

Table 1: Recovery profile of method.

\begin{tabular}{ccc}
\hline Spiked concentration $(\mathbf{m c g} / \mathbf{m l})$ & Concentration obtained $(\mathbf{m c g} / \mathbf{m l})$ & \% Recovery \pm RSD \\
\hline $\mathbf{1 0}$ & 9.68 & $96.80 \%$ \\
$\mathbf{2 0}$ & 19.26 & $96.30 \%$ \\
$\mathbf{3 0}$ & 28.79 & $95.97 \%$ \\
$\mathbf{4 0}$ & 39.35 & $98.38 \%$ \\
$\mathbf{5 0}$ & 48.66 & $97.32 \%$ \\
Total & & $\mathbf{9 6 . 9 6} \pm \mathbf{0 . 0 0 9 8}$ \\
\hline
\end{tabular}

Table 2: Mean pharmacokinetic profile of paracetamol (1000 mg) oral administration in human volunteers.

\begin{tabular}{|c|c|c|c|c|}
\hline $\begin{array}{l}\text { Pharmacokinetic } \\
\text { parameters }\end{array}$ & $\begin{array}{l}\text { Paracetamol } \\
\text { alone }\end{array}$ & $\begin{array}{l}\text { Paracetamol } \\
\text { + Yoyo bitters } \\
\text { (Concurrent) }\end{array}$ & $\begin{array}{l}\text { Paracetamol } \\
+ \text { Yoyo bitters } \\
\text { (Delayed) }\end{array}$ & p-value \\
\hline $\mathbf{K}_{a}\left(\mathbf{h}^{-1}\right)$ & $1.98 \pm 0.63$ & $2.17 \pm 0.94$ & $2.24 \pm 0.40$ & $\mathrm{P}>0.05$ \\
\hline $\mathbf{t}_{1 / 2 a}(\mathbf{h})$ & $0.35 \pm 0.05$ & $0.32 \pm 0.02$ & $0.31 \pm 0.02$ & $\mathrm{P}>0.05$ \\
\hline$C_{\max }(\mu \mathrm{g} / \mathrm{ml})$ & $20.00 \pm 6.41$ & $21.28 \pm 1.91$ & $22.00 \pm 2.53$ & $\mathrm{P}>0.05$ \\
\hline $\mathbf{T}_{\max }(\mathbf{h})$ & $0.80 \pm 0.20$ & $0.57 \pm 0.08$ & $0.90 \pm 0.28$ & $\mathrm{P}>0.05$ \\
\hline AUCo- $\infty(\mu \mathrm{g} . \mathbf{h} / \mathrm{ml})$ & $98.15 \pm 1.02$ & $102.00 \pm 2.01$ & $172.66 \pm 1.83$ & $\mathrm{P}<0.05$ \\
\hline $\mathbf{K}_{\beta}\left(\mathbf{h}^{-1}\right)$ & $0.2049 \pm 0.03$ & $0.2234 \pm 0.07$ & $0.0953 \pm 0.01$ & $\mathrm{P}<0.05$ \\
\hline $\mathbf{t}_{1 / 2 \beta}(h)$ & $3.38 \pm 0.22$ & $3.10 \pm 0.34$ & $7.27 \pm 0.72$ & $\mathrm{P}<0.05$ \\
\hline $\mathrm{Cl}_{\mathrm{T}} / \mathrm{F}(\mathrm{ml} / \mathrm{min})$ & $170.00 \pm 1.92$ & $163.40 \pm 3.04$ & $96.60 \pm 4.18$ & $\mathrm{P}<0.05$ \\
\hline
\end{tabular}




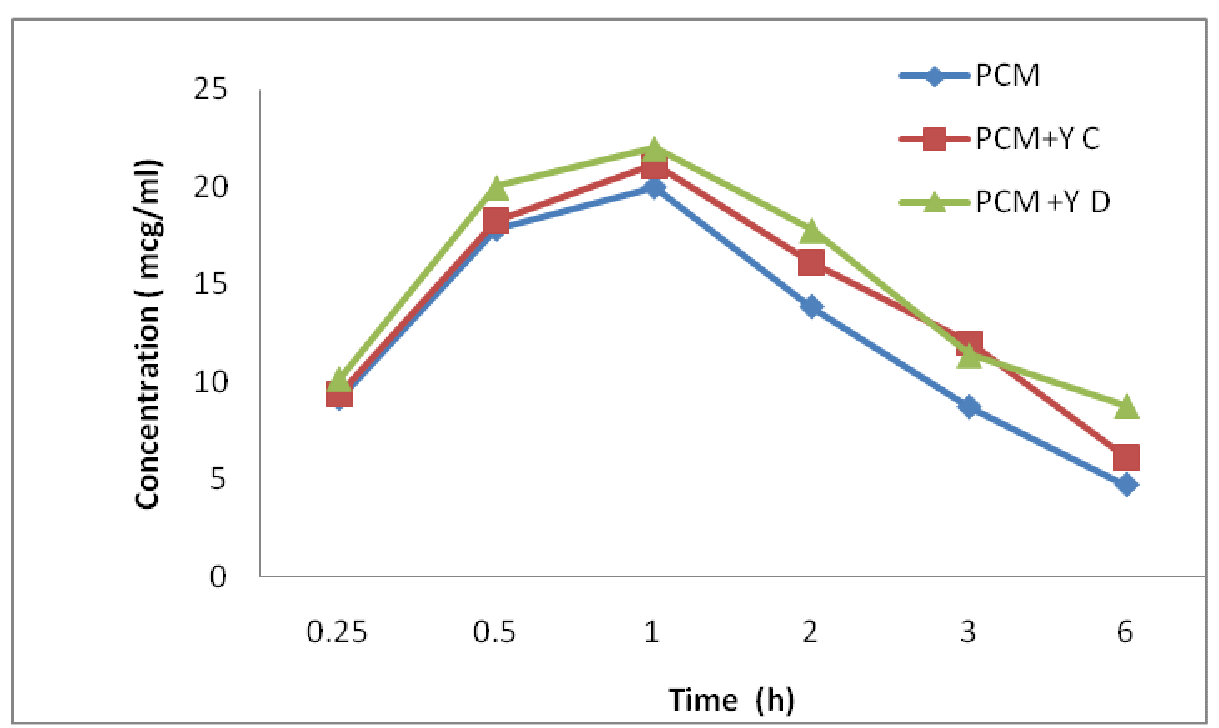

Figure 1: Plot of plasma concentration of oral single dose $(1000 \mathrm{mg})$ paracetamol against time. Key: PCM - Paracetamol alone; PCM +Y /C- - Paracetamol and Yoyo bitters (concurrent administration); PCM +Y /D- Paracetamol and Yoyo bitters (delayed administration).

\section{DISCUSSION}

The values obtained for the pharmacokinetics parameters are generally similar to previously reported values, Flower et al. (1985). The absorption rate constant $\left(\mathrm{K}_{\alpha}\right)$ was found to be $1.98 \mathrm{~h}^{-1}, 2.17 \mathrm{~h}^{-1}$ and $2.24 \mathrm{~h}^{-1}$ for paracetamol alone, concurrent administration of paracetamol and Yoyo bitters, and for delayed paracetamol administration respectively. Also the absorption half life $t_{1 / 2 \alpha}$ was found to be $0.34 \mathrm{~h}$, $0.32 \mathrm{~h}$ and $0.31 \mathrm{~h}$ for paracetamol alone, concurrent administration of paracetamol and Yoyo bitters, and for delayed administration of paracetamol two hours after administration of Yoyo bitters respectively (Table 2). These values did not show statistically significant differences $(\mathrm{P}>0.05)$, indicating that Yoyo bitters did not significantly affects the absorption of paracetamol in the gastrointestinal tract at the experimental dose.

The $\mathrm{C}_{\max }$ was found to be $20.00 \pm 3.41$ $\mu \mathrm{g} / \mathrm{ml}$ for paracetamol alone, $21.28 \pm 1.91$ $\mu \mathrm{g} / \mathrm{ml}$ for concurrent administration of paracetamol and Yoyo bitters, and $22.00 \pm$ $2.25 \mu \mathrm{g} / \mathrm{ml}$ for delayed administration of paracetamol after administration of Yoyo bitters with their corresponding $\mathrm{T}_{\max }$ as $0.80 \mathrm{~h}$, $0.87 \mathrm{~h}$, and $0.90 \mathrm{~h}$ respectively. These values agree with that reported by Shamba and Adotey (1982) as $18.12 \pm 1.29 \mu \mathrm{g} / \mathrm{ml}$. These values show a little percentage increase in the $\mathrm{C}_{\max }$ and $\mathrm{T}_{\max }$, but not statistically significant $(\mathrm{P}>0.05)$.

The AUCo- $\infty$ obtained were $98.15 \pm$ $1.02,102.00 \pm 2.01$ and $172.66 \pm 1.83 \mu \mathrm{g} . \mathrm{h} / \mathrm{ml}$ for paracetamol alone, paracetamol with Yoyo Bitters concurrently administered and paracetamol with Yoyo Bitters delayed administration respectively. There is no statistically significant difference in the AUCo- $\infty$ the concurrent administration protocol. There is significant increase $(\mathrm{P}<0.05)$ in $\mathrm{AUCo}-\infty$ in the delayed protocol as compared with the control. The elimination rate constant $\mathrm{K}_{\beta}$ were found to be $0.2049 \pm$ $0.03,0.2234 \pm 0.07$ and $0.0952 \pm 0.01 \mathrm{~h}^{-1}$ for paracetamol alone, paracetamol and Yoyo bitters concurrently and paracetamol and yoyo bitters delayed respectively. There are no significant changes between the values of paracetamol alone and when concurrently administered with Yoyo bitters. However there was a statistically significant $(\mathrm{P}<0.05)$ 
decrease from $0.2049 \mathrm{~h}^{-1}$ to $0.0953 \mathrm{~h}^{-1}$. This therefore suggests that Yoyo bitters have decreased the rate of elimination of paracetamol from the body.

The elimination half lives $\left(t_{1 / 2}\right)$ were found to be $3.38 \mathrm{~h}, 3.10 \mathrm{~h}$ and $7.27 \mathrm{~h}$. These values though within the range reported in literature are higher than those previously reported in Africans (Dasgupta et al., 2008). The $t_{1 / 2 \beta}$ was found to be longer with Yoyo bitters delayed paracetamol administration protocol. This increase was statistically significant $(\mathrm{P}<0.05)$. This implies that Yoyo bitters increases the time taken for half of the concentration of paracetamol that reaches the plasma to be eliminated. This is similar to the effect of grape fruit juice on paracetamol. (Dasgupta et al., 2008),

The Total oral Clearance $(\mathrm{Cl} / \mathrm{F})$ of paracetamol obtained were $170.00 \mathrm{ml} / \mathrm{min}$, $163.40 \mathrm{ml} / \mathrm{min}$, and $96.60 \mathrm{ml} / \mathrm{min}$ for paracetamol alone, paracetamol with Yoyo Bitters concurrently administered and paracetamol with Yoyo Bitters 'delayed' administration respectively. The percentage change in the clearance of paracetamol when administered concurrently with paracetamol was found not to be significant, but there was significant decrease $(\mathrm{P}<0.05)$ in paracetamol $\mathrm{Cl} / \mathrm{F}$ for the delayed administration protocol. These results suggest that systemic clearance of paracetamol was affected by Yoyo bitters when paracetamol is administered after the constituents of Yoyo bitters has sufficiently saturated the system, and had therefore possibly influenced metabolic enzyme activities.

Paracetamol is metabolized in the liver by CYP1A1, 1A2, 2E1, and 3A4 (Raucy et al., 1989), and to a little extent by CYP2D6. Yoyo bitters is a herbal preparation made from a blend of various parts and fruits of plants such as Aloe vera, Acinos arvensis, Chenopodium murale, Cinamum aromatic and Citrus aurantifolia. Citrus aurantifolia is a lime and might be containing similar chemical constituents as found in grape fruit juice, a potent inhibitor of the hepatic Cytochrome P-
450 system (specifically CYP3A4) (Eagling et al., 1999). Samojlik et al. (2002) reported a decreased metabolic rate of paracetamol by grape fruit juice. Therefore the delay in paracetamol disposition might be due to inhibition of the enzyme CYP3A4 responsible for its metabolism. The observed prolonged time of clearance might lead to possible accumulation of paracetamol when administered three to four times daily thereby making it available for CYP2D6 to act on, which might lead to the production of the undesirable metabolite, N-acetyl-p-benzoquinone imine (NAPQI). Paracetamol toxicity is attributed to NAPQI. At usual doses, NAPQI is quickly detoxified by conjugation. Following overdose, accumulated paracetamol and possibly extensive and ultra rapid metabolizers, this detoxification pathway becomes saturated and consequently NAPQI accumulates (www.wikipedia.org, 2009).

\section{Conclusion}

From the results obtained there were no statistically significant changes in the absorption parameters $\left(K \alpha, t_{1 / 2}, C_{\max }, T_{\max }\right)$ when paracetamol and Yoyo bitters were concurrently administered. The elimination parameters $\left(\mathrm{K}_{\beta}, \mathrm{t}_{1 / 2 \beta}, \mathrm{Cl}_{\mathrm{T} / \mathrm{F}} \mathrm{F}\right)$ as well as the AUCo- $\infty$ showed significant changes $(\mathrm{P}<0.05)$ in the delayed protocol, indicating that the constituents of Yoyo bitters inhibits paracetamol metabolism. Based on these results, it is advised that for the desired therapeutic effects of paracetamol to be achieved with minimal or no toxicity, they should be administered at different times.

\section{REFERENCES}

Adzu B, Garba M, Haruna A, Maman M, Wambebe C, Gamaniel K. 2001. Effect of niprisan on single oral dose pharmacokinetics of paracetamol in rats. Eur. J. Drug Metab. Pharmacokinet., 26(3): 201- 204.

Dasgupta A, Reyes MA, Risin SA, Actor JK. 2008. Interaction of white and pink 
grapefruit juice with acetaminophen (Paracetamol) in vivo in Mice. $J$. Medicinal Food., 11(4): 795-798.

Desta Z, Soukhova NV, Flockhart DA. 2001. Inhibition of cytochrome P450 (CYP450) isoforms by isoniazid: potent inhibition of CYP2C19 and CYP3A4. J. Chromatogr. B. Biomed. Sci. Appl., 45(2): 382-392.

Eagling VA, Profit L, Back DJ. 1999. Inhibition of the CYP3A4-mediated metabolism and P-glycoprotein-mediated transport of the HIV-1 protease inhibitor saquinavir by grapefruit juice components. Bri. J. Clinical Pharmacol., 48(4): 543-552.

Emby DJ, Fraser BN. 1977. Hepatotoxicity of paracetamol enhanced by ingestion of alcohol. South African Med. Journal, 51: 208-209.

Flower RJ, Vane JR. 1972. Inhibition of Prostaglandin Synthetase in Brain Explains the Anti-pyretic Activity of Paracetamol (4-acetamidophenol). Nature, 240: 410-411.

Fugh-Berman A, Ernst E. 2001. Herb-drug Interactions: Review and Assessment of Report Reliability, Bri. J. Clinical Pharmacol., 52(5): 587-595.

Fugh-Berman A. 2003. Herb-drug interactions. The Lancet, 355 (9198): 134-138 A.

Fukuda K, Guo L, Ohashi N, Yoshikawa M, Yamazoe Y. 2000. Amounts and variation in grapefruit juice of the main components causing grapefruit-drug interaction. J. Chromatogr. B. Biomed. Sci. Appl., 741(2): 195-203.
Glynn JP, Kandel ES. 1975. Paracetamol measurement. Lancet, 1: 1147 - 1158.

Kolawole JA, Maduenyi A. 2004. Effect of 'Zobo' Drink (Habiscuss sabdariffa water extract) on the pharmacokinetics of paracetamol. Eur. J. Drug Metab. and Pharmacokniet., 29: 25-29.

Raucy JL, Lasker JM, Lieber CS, Black M. 1989. Acetaminophen activation by human liver cytochromes P450IIE1 and P450IA2. Arch. Biochem. Biophys., 271: 270-283.

Roby CA, Anderson GD, Kantor E, Dryer DA, Burstein AH. 2000. St John's Wort: Effect on CYP3A4 activity. Clin. Pharmacol. Ther., 67: 451-457.

Samojlik I, Đaković-Švajcer K, Mikov M. 2002. The influence of single or multiple grapefruit juice intake on paracetamol pharmacokinetics and toxicity. Acta biologica iugoslavica - serija C: Physiologica et pharmacologica Acta, 38(1): 7 - 16 .

Shamba E, Adotey J. 1982. http://www.uz.ac.zw/medicine/pharmacy/ pubs/html.

Tripathi YB, Tiwari OP, Nagwani S, Mishra B. 2009. Pharmacokinetic-interaction of Vitex negundo Linn. and paracetamol. Indian J. Med. Res.., 130(4): 479-483.

Villenuve JP, Raymond G, Bruneau J, Colpron L, Pomier-Layrargues G. 1983. Pharmacokinetics and metabolism of acetaminophen in normal, alcoholic and cirrhotic subjects. Gastroenterol. Clin. Biol., 7: 898 - 902.

(http://www.wikipedia.org,. 2009. 04. 2010. 